\title{
Práticas e Movimentos Epistêmicos na Análise dos Resultados de uma Atividade Prática Experimental Investigativa
}

\section{Practices and Epistemic Movements in the Analysis about the Results of an Experimental Inquiry Practical Activity}

\section{Ana Elisa Montebelli Motta ${ }^{a}$; Michele Dayane Facioli Medeiros ${ }^{a}$; Marcelo Tadeu Motokane $^{\mathrm{b}}$}

a Instituto de Física, Universidade de São Paulo, São Paulo, Brasil - anaemmotta@gmail.com; micheledfmedeiros@hotmail.com

b Departamento de Biologia, Universidade de São Paulo, Ribeirão Preto, Brasil - mtmotokane@ffclrp.usp.br

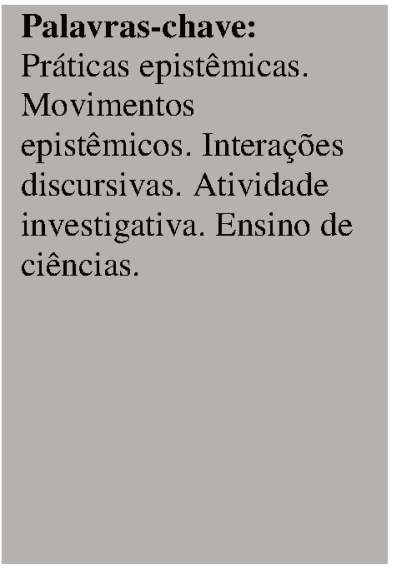

Palavras-chave:

Práticas epistêmicas.

Movimentos investigativa. Ensino de ciências.
Resumo: Este trabalho insere-se nos estudos sobre as interações discursivas no Ensino de Ciências. O objetivo é verificar quais Práticas Epistêmicas e Movimentos Epistêmicos estão presentes ao longo da análise dos resultados de uma atividade prática experimental investigativa. Assim, pretende-se caracterizar como ocorreu a proposição de explicações para o problema nas interações entre professores e estudantes. Para isso, foram selecionados dois episódios de uma aula sobre o tema fotossíntese e respiração, realizada com alunos do $7^{\circ}$ ano do Ensino Fundamental. Nossos resultados indicam as contribuições dos professores de modo que os estudantes pudessem passar da formulação de hipóteses, pautadas principalmente na identificação da luz como variável experimental, para o desenvolvimento de explicações que incorporassem os conceitos. A retomada de informações já trabalhadas possibilitou o ordenamento de dados, o que pareceu importante para que os alunos organizassem informações e estabelecessem bases conceituais para a posterior interpretação dos dados obtidos.
Abstract: This paper is inserted in the studies about discursive interactions in Science Teaching. The goal is to verify which Epistemic Practices and Epistemic Movements are present throughout the analysis of the results in an experimental inquiry practical activity. Thus, it is intended to characterize the proposition of explanations in the interactions between teachers and students. For this, we selected two episodes of a class about the photosynthesis and respiration theme, taught with students of the 7th Middle School. Our results indicate the teachers' contributions in order that the students could move from the hypothesis formulation', based on the identification of the light as the experimental variable, to the development of explanations that incorporated the concepts. The resume of prior information allows the ordering of data, which seemed to be important for students to organize information and establish conceptual bases for the subsequent interpretation of the obtained data. 


\section{Introdução}

Os aspectos epistêmicos e o Ensino de Ciências

A influência de uma perspectiva sociocultural na pesquisa em Ensino de Ciências tem resultado em investigações sobre como o conhecimento é construído no âmbito social da sala de aula. As proposições de Vygotsky e Bakhtin enfatizam as origens sociais dos processos mentais e a importância da linguagem enquanto recurso semiótico, em oposição à visão que descrevia a aprendizagem como processo majoritariamente individual até a década de 1990 (MORTIMER; SCOTT, 2003; GIORDAN, 2008). As novas compreensões passam a considerar a sala de aula como espaço dialógico no qual o sujeito se constitui na interação com o outro, interações essas determinadas por fatores históricos, culturais e institucionais (GIORDAN, 2008). A aprendizagem não é mais vista como uma substituição de concepções prévias pelos conceitos científicos, mas como uma negociação de significados em um ambiente comunicativo (MORTIMER; SCOTT, 2003).

Em tal percepção, a aprendizagem da ciência é inseparável da aprendizagem da linguagem científica, manifestando-se nas interações discursivas desenvolvidas entre professor e alunos (MORTIMER; SCOTT, 2003). Segundo Lemke (1990), ensinar, aprender e fazer ciência são igualmente processos sociais, nos quais crenças, valores, conhecimentos e atitudes são compartilhados por uma comunidade que se constitui pela linguagem. Para o autor, a ciência tem um discurso próprio e aprender ciência envolve não apenas falar sobre ciência, mas também expressar-se por meio de seu discurso. "Falar ciência" implica em observar, descrever, avaliar, comparar, classificar, questionar, concluir ou, em outras palavras, desempenhar práticas que são típicas de uma cultura científica (LEMKE, 1990).

Desse modo, tanto a ciência quanto sua aprendizagem envolvem práticas que são inerentemente epistêmicas, ou seja, incluem critérios e valores que sustentam um modo próprio de ver, pensar e falar sobre a realidade (SANDOVAL; MORRISON, 2003). Entendese que o conhecimento científico produz enunciados, conclusões, hipóteses e teorias que não constituem meras opinióes, mas devem estar sustentadas em dados empíricos ou bases teóricas (JIMÉNEZ-ALEIXANDRE, 2006).

Kelly e Duschl (2002) destacam a importância dos estudos epistemológicos no Ensino de Ciências, de modo que se possa evidenciar a construção de significados na sala de aula por uma comunidade que decide o que conta como conhecimento, bem como as formas adequadas de construí-lo. Kelly (2005) considera uma mudança no foco do sujeito epistêmico: de conhecedor individual para uma comunidade de conhecedores que possuem práticas socioculturais derivadas de uma história em comum. Essas práticas sociais são constituídas de um conjunto de ações realizadas por indivíduos que compartilham valores e ferramentas culturais. Assim, o conceito de Práticas Epistêmicas pode ser compreendido 
como as formas pelas quais os membros de uma comunidade propõem, justificam, avaliam e legitimam enunciados para a produção de conhecimento (KELLY; DUSCHL, 2002; SANDOVAL; MORRISON; 2003; SANDOVAL; REISER, 2004; JIMÉNEZALEIXANDRE et al., 2008).

Diversos trabalhos relacionados ao ensino e aprendizagem têm dado foco às interações e diálogos existentes entre os alunos e professores na busca de um entendimento da dimensão epistêmica (e.g., JIMÉNEZ-ALEIXANDRE et al., 1998; KELLY; DUSCHL, 2002; KELLY; TAKAO, 2002; TAKAO; KELLY, 2003; SANDOVAL; MORRISON, 2003; SANDOVAL; RESIER, 2004; JIMÉNEZ- ALEIXANDRE et al., 2008; LIDAR et al., 2005; SILVA, 2015). Dentre as ferramentas analíticas propostas, Jiménez-Aleixandre et al. (2008) sugerem Práticas Epistêmicas específicas, tendo-se em vista as instâncias sociais de produção, comunicação e avaliação do conhecimento propostas por Kelly (2005).

Outros trabalhos se dedicam mais especificamente a compreender a influência e papel do professor nesse contexto. Lidar et al. (2005) sugerem Movimentos Epistemológicos, que podem ser entendidos como os modos pelos quais os professores orientam os estudantes sobre o que conta como conhecimento relevante e os meios apropriados para a construção dos conceitos científicos. Silva (2011), considerando essa proposta, sugere os Movimentos Epistêmicos. Tais categorias referem-se às intervenções dos professores, caracterizadas como questionamentos, sugestões e orientações que são significativas para o desenvolvimento de determinadas práticas no decorrer de atividades investigativas.

Utilizando as ferramentas de Práticas e Movimentos Epistêmicos, Silva (2015) analisou as interações discursivas em uma atividade investigativa sobre densidade e flutuação, realizada com estudantes do $9^{\circ}$ ano do Ensino Fundamental. Segundo a pesquisadora, percebendo que os estudantes expressavam pouca relação entre o fenômeno observado e os conceitos científicos, a professora chamou a atenção para aspectos familiares e insistiu para que incorporassem conceitos já trabalhados, de modo que os alunos passaram a elaborar suas hipóteses considerando os conceitos químicos. Assim, Silva (2015) identificou o desenvolvimento de práticas próximas à natureza científica e pode descrever a importância do papel da professora no seu aparecimento. Neste trabalho, também propomos analisar as práticas desempenhadas pelos estudantes, bem como as ações de quem conduz uma atividade prática experimental investigativa.

As atividades práticas experimentais investigativas

Hodson (1994), Filho (2001) e Raboni (2002) consideram as atividades práticas uma modalidade de ensino em que há a participação ativa dos alunos, podendo essa ser um trabalho de campo, observações, vídeos ou filmes em que os estudantes realizam registros, 
confecções de pôsteres, análises de tabelas e gráficos, trabalhos laboratoriais, demonstrações, dentre outras ações. As atividades práticas experimentais, por sua vez, podem ser compreendidas como aulas, realizadas no laboratório ou em sala de aula convencional, que envolvem a manipulação de materiais e o controle de variáveis (HODSON, 1994).

No ideário dos professores, tais atividades são muitas vezes consideradas imprescindíveis e tidas como a representação de uma boa aula de ciências. $\mathrm{Na}$ pesquisa realizada por Ramos e Rosa (2008), professores afirmam que os alunos aprendem mais quando participam de atividades práticas, apesar de nunca terem de fato realizado essas atividades com seus alunos. No trabalho de Galliazzi et al. (2001), participantes de um curso de formação para professores de química creditam grande importância às atividades experimentais, sem questioná-las em nenhuma instância. Hodson (1994) alerta que muitos dos aspectos positivos sobre as atividades experimentais carecem de uma reflexão de suas reais funções nos processos de ensino e aprendizagem e, como consequência, suas execuções são confusas e de baixo valor educacional.

Alguns autores apontam que, quando existem, as atividades práticas experimentais são comumente ministradas de forma mecânica e superficial, de modo que os alunos cumprem etapas pré-determinadas com o objetivo de comprovar os estudos teóricos (AXT, 1991; GIL PERÉZ; CASTRO, 1996; SILVA; ZANON, 2000; CARVALHO, 2006). Nesse sentido, as atividades experimentais praticadas em sala de aula são opostas à sugestão expressa pelos Parâmetros Curriculares Nacionais para o Ensino de Ciências (PCNs), que orientam:

[...] É muito importante que as atividades não se limitem a nomeações e manipulações de vidrarias e reagentes, fora do contexto experimental. É fundamental que as atividades práticas tenham garantido o espaço de reflexão, desenvolvimento e construção de ideias, ao lado de conhecimentos de procedimentos e atitudes [...] Também durante a experimentação, a problematização é essencial para que os estudantes sejam guiados em suas observações (BRASIL, 1998, p. 122).

As pesquisas em Ensino de Ciências também têm enfatizado que as atividades experimentais demandam outro enfoque, propondo a abordagem investigativa como uma alternativa (GIL PERÉZ; CASTRO, 1996; BORGES, 2002; CARVALHO, 2006; 2013). Segundo Silva (2015), a premissa de que o ensino de ciências deve proporcionar ao aluno não apenas a aquisição de termos e conceitos, mas também uma compreensão da natureza do conhecimento científico, dá suporte ao planejamento de ambientes investigativos e aos trabalhos que se dedicam a compreender como as estruturas das atividades investigativas podem favorecer o desenvolvimento de determinadas Práticas Epistêmicas.

Para Carvalho (2013), as atividades investigativas devem ser planejadas do ponto de vista do material e das interações, sendo caracterizadas pela proposição de um problema (experimental ou teórico) cuja resolução exija o diálogo e permita a liberdade intelectual dos estudantes. Em oposição às propostas tradicionais de ensino, nas quais o professor é 
caracterizado como o detentor do saber e os alunos como meros receptores, o ensino por investigação pode proporcionar condições para que o aluno construa seu próprio conhecimento (CARVALHO, 2013).

Zômpero e Laburú (2001), em revisão da literatura, identificaram pontos de congruência para as distintas abordagens metodológicas propostas para o ensino por investigação, que incluem: o engajamento dos alunos para realizar as atividades; a proposição de hipóteses; o levantamento de conhecimentos prévios; a busca por informações, tanto por meio dos experimentos quanto na bibliografia que possa ser consultada, e a comunicação dos estudos para os demais colegas. Em suma, espera-se que, durante a investigação, os estudantes sejam envolvidos em práticas que são peculiares à construção do conhecimento científico, aproximando-se do modo de pensar e falar da ciência.

Portanto, compreendemos que as atividades práticas experimentais investigativas são aquelas que vão além da simples manipulação de materiais, possibilitando aos alunos uma ação reflexiva sobre os conceitos científicos e a própria produção do conhecimento.

Ancorado nesses pressupostos, o presente estudo tem como objetivo analisar uma atividade prática experimental investigativa. Pretende-se identificar Práticas Epistêmicas nas interações discursivas e Movimentos Epistêmicos para as ações dos professores, de modo a caracterizar como as explicações para o problema proposto aos estudantes puderam ser construídas no âmbito social da sala de aula.

\section{Metodologia}

Sobre a coleta dos dados e os sujeitos da pesquisa

Os dados procedem de uma aula investigativa com duração total de cem minutos. A aula foi registrada em uma câmera posicionada no canto esquerdo frontal da sala, manuseada por uma das pesquisadoras. Assim, foram obtidas imagens panorâmicas e outras com maior proximidade, quando a câmera era focada no sujeito que dispunha da fala. A gravação foi transcrita integralmente e procurou-se reproduzir de forma fidedigna as falas de professores e alunos, os quais tiveram seus nomes preservados. Ambos foram identificados como Professor ou Aluno $n$, sendo $n$ um número em sequência na identificação dos sujeitos durante a transcrição das falas.

A turma era composta por 29 alunos, entre onze e treze anos, pertencentes ao $7^{\circ}$ ano do Ensino Fundamental de uma escola pública municipal localizada no interior do estado de São Paulo. A aula foi planejada e executada por três professores de Biologia em formação, que integravam o Programa Institucional de Bolsa de Iniciação à Docência (PIBID). Presente em vários estados da federação, o PIBID tem como objetivo aperfeiçoar e valorizar a formação de professores, incentivando a atuação de estudantes universitários na educação 
básica.

As atividades desenvolvidas durante a aula

A aula registrada em vídeo passou por um processo de mapeamento. Foram identificados quatro grandes momentos, que se referem às atividades realizadas durante a aula: 1) Levantamento de conhecimentos prévios; 2) Entrando em contato com os materiais: o experimento com o canudo; 3) Resolvendo problemas envolvendo a utilização do material: o gelo seco e 4) Interpretação e discussão dos resultados do experimento.

$\mathrm{Na}$ atividade de levantamento de conhecimentos prévios, os professores dedicaram-se a levantar os conhecimentos que os alunos já possuíam sobre o tema a ser trabalhado, sem que houvesse, a princípio, uma preocupação com a organização das informações. Na segunda e na terceira atividade, os estudantes manusearam tubos de ensaio contendo a substância química vermelho de cresol e dedicaram-se a resolver pequenos problemas utilizando o material. $\mathrm{Na}$ atividade final, os estudantes interpretaram e discutiram os resultados do experimento central da aula, buscando estabelecer relações entre os dados prévios, os dados obtidos, a variável experimental e os conceitos de fotossíntese e respiração.

Para cada atividade realizada na aula foram selecionados episódios. A ideia de episódio é uma adaptação da definição de evento na tradição da etnografia interacional. Os episódios podem ser definidos como um segmento do discurso com início e fim claros em termos de conteúdo temático, fase didática ou tarefa desenvolvida. Suas fronteiras são delimitadas por pistas contextuais verbais e não verbais, que incluem gestos, movimentos corporais dos participantes e as formas pelas quais se posicionam no ambiente e interagem entre si e com os recursos materiais (MORTIMER et al., 2007). Os episódios contextualizam as ações e o discurso de sala de aula, de modo que auxiliam o pesquisador na compreensão do andamento das interações discursivas, possibilitando uma análise panorâmica da situação (SILVA, 2008). Cada episódio é composto por um agrupamento de turnos, que correspondem à fala transcrita de cada interlocutor. Os turnos de fala constituem a menor unidade de análise deste trabalho e foram utilizados para a identificação das categorias de Práticas e Movimentos Epistêmicos. O Quadro 1 apresenta de forma sintética a organização da aula a partir dos episódios e os turnos de fala que abrangem, situando-os dentro de cada atividade. 
Quadro 1 - Síntese dos episódios mapeados.

\begin{tabular}{|c|c|c|c|c|c|}
\hline Atividade & $\begin{array}{l}\text { Número do } \\
\text { episódio }\end{array}$ & $\begin{array}{l}\text { Duração } \\
\text { (min) }\end{array}$ & $\begin{array}{l}\text { Turnos } \\
\text { inclusos }\end{array}$ & $\begin{array}{l}\text { Total de } \\
\text { turnos }\end{array}$ & Breve descrição do episódio \\
\hline $\begin{array}{l}\text { Levantamento de } \\
\text { conhecimentos prévios }\end{array}$ & 1 & 01:03 & $5-30$ & 26 & $\begin{array}{l}\text { Levantamento de } \\
\text { conhecimentos prévios sobre } \\
\text { fotossíntese e respiração }\end{array}$ \\
\hline \multirow{4}{*}{$\begin{array}{l}\text { Entrando em contato com } \\
\text { os materiais: o } \\
\text { experimento com o } \\
\text { canudo }\end{array}$} & 2 & $03: 06$ & $31-42$ & 12 & $\begin{array}{c}\text { Os estudantes sopram com } \\
\text { um canudo o tubo contendo o } \\
\text { indicador }\end{array}$ \\
\hline & 3 & $00: 10$ & $59-62$ & 4 & $\begin{array}{l}\text { Construção do dado sobre o } \\
\text { indicador }\end{array}$ \\
\hline & 4 & $05: 58$ & $71-83$ & 13 & $\begin{array}{c}\text { Ressignificação do } \\
\text { experimento a partir do dado }\end{array}$ \\
\hline & 5 & $01: 23$ & $96-104$ & 9 & Sistematização do dado \\
\hline $\begin{array}{l}\text { Resolvendo problemas } \\
\text { envolvendo a utilização } \\
\text { do material: o gelo seco }\end{array}$ & 6 & $07: 13$ & $135-160$ & 26 & $\begin{array}{l}\text { Os estudantes colocam gelo } \\
\text { seco em contato com o } \\
\text { indicador }\end{array}$ \\
\hline \multirow{2}{*}{$\begin{array}{l}\text { Interpretação e discussão } \\
\text { dos resultados do } \\
\text { experimento }\end{array}$} & 7 & $12: 23$ & $161-215$ & 55 & $\begin{array}{l}\text { Levantamento de hipóteses e } \\
\text { construção do dado para o } \\
\text { experimento da fotossíntese }\end{array}$ \\
\hline & 8 & $20: 03$ & $246-382$ & 137 & $\begin{array}{c}\text { Construção de uma } \\
\text { explicação para o problema }\end{array}$ \\
\hline
\end{tabular}

Fonte: elaborado pelos autores.

As atividades especificadas integraram uma sequência didática investigativa maior, que abordou as características dos seres vivos (ver ANEXO I). A aula considerada neste estudo teve como objetivo levar os estudantes a reconhecerem que as plantas realizam os processos de fotossíntese e respiração. A quarta atividade, experimento central da aula, consistiu na utilização de um indicador de $\mathrm{pH}$ (vermelho de cresol), que torna possível observar, de forma indireta e qualitativa, a relação entre a fotossíntese e a respiração. Tal indicador é encontrado no mercado na forma de pó cristalino na cor vermelha e é solúvel em água. Em um meio ácido, a solução de vermelho de cresol apresenta uma coloração alaranjada, enquanto em meio básico adquire uma coloração arroxeada.

A solução foi utilizada pelos alunos na montagem de três tubos de ensaio. No primeiro tubo foram colocadas folhas coletadas de uma árvore. As folhas foram dispostas de maneira que não houvesse contato entre elas e a solução de vermelho de cresol. O tubo 1 foi tampado com papel filme e em seguida embrulhado no papel alumínio. No tubo 2 foram colocadas folhas de maneira semelhante à do tubo 1 , porém esse não foi coberto com papel alumínio. Já o tubo 3 continha apenas a solução de vermelho de cresol e foi utilizado como um controle negativo. Todos os tubos foram acomodados em uma estante e posicionados próximos a uma lâmpada incandescente.

No caso do experimento realizado, quando a taxa de respiração supera a de fotossíntese, a quantidade de gás carbônico liberado no meio torna-se maior. Seu contato com 
a solução de vermelho de cresol provoca a formação de ácido carbônico, o que faz com que o indicador adquira uma tonalidade laranja. Por outro lado, quando a taxa de fotossíntese é similar à respiratória, o consumo e a produção de gás carbônico entram em equilíbrio. Nesse caso, a cor do indicador não é alterada como no processo descrito anteriormente.

Neste trabalho, nos deteremos aos episódios 7 e 8 , nos quais estudantes e professores interpretam e discutem os resultados experimentais. Assim, analisaremos as Práticas Epistêmicas durante a construção de uma explicação para o problema, bem como os Movimentos Epistêmicos dos professores que contribuíram para seu aparecimento. Salientamos que nas demais atividades outras Práticas e Movimentos Epistêmicos foram verificados.

Sistema de categorias

As interações discursivas foram analisadas a partir de dois sistemas de categorias. Partimos das Práticas Epistêmicas empregadas por Lima-Tavares (2009), adaptadas de Silva (2008), e categorias adicionais empregadas por Silva (2015). Ambas tratam de uma adequação daquelas inicialmente propostas por Jiménez-Aleixandre et al. (2008). A seguir são definidas as instâncias sociais e suas Práticas Epistêmicas. Ressaltamos que definimos apenas aquelas verificadas nas análises.

A instância social de produção do conhecimento corresponde aos momentos em que os alunos articulam seus saberes, propondo questões e levantando hipóteses, planejando e realizando experimentos para construção e significação dos dados obtidos ou fornecidos. Para essa instância, foram identificadas as seguintes práticas:

a) Configurando hipóteses: quando os alunos expõem de forma sintética suas previsões.

b) Considerando dados e conceitos para elaborar hipóteses: quando, para elaborar suas hipóteses, os alunos recorrem a conceitos e/ou dados que já possuem ou já foram trabalhados durante a atividade.

c) Articulando conhecimento observacional e conceitual: quando os alunos expõem a relação entre os conceitos e os aspectos observáveis do fenômeno em investigação.

d) Concluindo: quando os estudantes apresentam a solução para o problema.

f) Construindo dados: corresponde a construção ou coleta dos dados, quando os estudantes ainda lidam com dados brutos.

g) Ordenando dados: quando os estudantes retomam dados já trabalhados, ordenando-os.

h) Monitorando o progresso: quando os alunos observam o andamento da atividade que estão desenvolvendo.

A instância social de comunicação refere-se aos momentos nos quais os alunos discutem ou textualizam os resultados encontrados. Os alunos interpretam os dados, 
estabelecem relações, traduzem linguagens e propõem explicações. Nessa instância, foi encontrada a prática:

a) Negociando explicações: quando os alunos negociam uma explicação, entre eles ou com o professor, com o objetivo de atingir um consenso.

A instância social de avaliação do conhecimento corresponde aos momentos em que os alunos avaliam ou justificam o conhecimento, estabelecendo relações entre teorias e dados. Nessa instância, foram identificadas as seguintes práticas:

a) Usando conceitos para interpretação dos dados: quando os estudantes passam a empregar conceitos para dar sentido aos dados trabalhados anteriormente.

b) Complementando ideias: quando o aluno complementa algo dito pelo professor ou outro colega.

c) Criticando outras declarações: quando o estudante apresenta críticas às ideias dos outros.

Para a análise das ações dos professores, foram utilizados os Movimentos Epistêmicos empregados por Silva (2011) e Nascimento et al. (2012). As categorias consideradas neste trabalho, conforme definição dos autores supracitados, foram:

a) Elaboração: corresponde às ações do professor que possibilitam aos alunos, comumente por meio de questionamentos, construir um olhar inicial sobre o fenômeno. São os questionamentos expressos nos roteiros de atividade ou mesmo proferidos oralmente pelo professor, os quais geram espaço para que os estudantes reflitam e exponham seus pontos de vista sobre os objetos e os eventos investigados.

b) Reelaboração: corresponde às ações do professor que instigam os alunos, por questionamentos ou afirmações, a notarem aspectos desconsiderados ou a trazerem à tona novas ideias, favorecendo uma modificação ou uma problematização do pensamento inicial.

c) Instrução: quando o professor apresenta explicitamente novas informações para os alunos.

d) Correção: quando o professor corrige explicitamente as afirmações e/ou os procedimentos desempenhados pelos alunos.

e) Compreensão: quando o professor busca compreender, por meio de questionamentos, determinados procedimentos e/ou ideias dos estudantes.

f) Confirmação: quando o professor concorda com as ideias apresentadas pelos alunos ou permite que eles executem determinados procedimentos que foram planejados.

g) Síntese: quando o professor explicita as principais ideias alcançadas pelos alunos.

\section{Resultados e discussão}

Episódio 7

O episódio tem início logo após a montagem do experimento. A princípio os estudantes monitoram o progresso, revendo as etapas já cumpridas. Um dos professores 
questiona os alunos sobre os possíveis resultados experimentais, ação que permite que os estudantes passem a configurar hipóteses. Alguns alunos sugerem que tenha ocorrido uma mudança na coloração do indicador ácido-base, outros afirmam que não. No turno 184, o professor solicita que os alunos justifiquem suas hipóteses. Os alunos continuam a configurar hipóteses, inicialmente identificando a luz como variável relacionada ao problema. No turno 188, a Aluna 11 passa a considerar dados e conceitos para elaborar hipóteses, sugerindo a presença do gás carbônico, mas sem justificar as relações para o evento. O Movimento Epistêmico verificado para o professor é o de elaboração, estimulando os estudantes a exporem suas percepções e formularem hipóteses sobre o fenômeno. O Quadro 2 traz o exemplo da sequência de interação.

Quadro 2 - Turnos de fala nos quais os estudantes configuram hipóteses.

\begin{tabular}{|c|c|c|c|}
\hline Turno & Transcrição das falas & Práticas Epistêmicas & Movimentos Epistêmicos \\
\hline 184 & $\begin{array}{l}\text { Professor 1: Então ó, tem duas opções: } \\
\text { mudou de cor e não mudou de cor. Aqui não } \\
\text { mudou de cor, continuou vermelho (aponta } \\
\text { para o tubo controle). Agora, tem um monte } \\
\text { de gente que falou que mudou de cor. Por } \\
\text { que mudou de cor? }\end{array}$ & & $\begin{array}{l}\text { Síntese } \\
\text { Elaboração }\end{array}$ \\
\hline 185 & Aluno 11: Por causa da planta. & & \\
\hline 186 & Aluno 5: Porque a planta não tinha luz. & Configurando hipótese & \\
\hline 187 & Aluno não identificado: Falta de oxigênio. & & \\
\hline 188 & $\begin{array}{l}\text { Aluna 11: Gás carbônico. A planta liberou } \\
\text { gás carbônico, aí ela fechada não entrou luz, } \\
\text { aí eu acho que mudou de cor. }\end{array}$ & $\begin{array}{l}\text { Considerando dados e } \\
\text { conceitos para elaborar } \\
\text { hipóteses }\end{array}$ & \\
\hline
\end{tabular}

Fonte: elaborado pelos autores.

No turno 192, os estudantes abrem os tubos e observam as mudanças ocorridas, construindo dados. Nesse trecho, o Movimento Epistêmico verificado foi o de síntese, de modo que o professor resume as ideias alcançadas sobre o novo dado (Quadro 3).

Quadro 3 - Turnos de fala nos quais os dados experimentais são construídos.

\begin{tabular}{cl|c}
\hline Turno & \multicolumn{1}{c}{ Transcrição das falas Práticas Epistêmicas } & \multicolumn{1}{c}{ Movimentos Epistêmicos } \\
\hline 192 & Alunos: Nossa! Ficou amarelo, laranja. & \\
\hline & $\begin{array}{l}\text { Aluno 14: Professor, olha o que a gente } \\
\text { acabou de ver. Esta ficou muito mais clara } \\
\text { (apontando para o tubo que estava na } \quad \text { Construindo dados } \\
\text { ausência da luz), esta ficou um pouco menos } \\
\text { clara (apontando para o tubo que recebeu } \\
\text { luz) e esta ficou vermelha (apontando para o } \\
\text { controle). }\end{array}$ & \\
\hline & $\begin{array}{l}\text { Professor 1: Legal ó, das duas que tem } \\
\text { plantinhas, uma ficou bem clara, } \\
\text { amarela/laranja, e a outra ficou mais ou } \\
\text { menos vermelho claro. }\end{array}$ & \\
\hline
\end{tabular}

Fonte: elaborado pelos autores. 
Em seguida, o problema central é colocado pelos professores: Por que o indicador apresenta uma coloração diferente em cada tubo? Logo após a construção do dado, os estudantes novamente configuram hipóteses, associando a variável experimental (presença/ausência de luz) à mudança de coloração. No entanto, ainda não estabelecem as relações entre os dados obtidos (coloração adquirida em cada tubo), os dados prévios (em solução ácida o indicador torna-se amarelo), a variável experimental e o conhecimento conceitual sobre fotossíntese e respiração. Ao longo da sequência de interação, há predominância do Movimento Epistêmico de síntese, na medida em que o professor resume os dados e a variável identificada pelos estudantes. Quadro 4 ilustra o momento.

Quadro 4 - Turnos de fala nos quais os estudantes configuram hipóteses a partir de variáveis.

\begin{tabular}{lll} 
Turno & \multicolumn{1}{c}{ Transcrição das falas } & Práticas Epistêmicas \\
\hline \multirow{2}{*}{$\begin{array}{l}\text { Aluno 9: Eu acho que essa daqui ficou } \\
\text { amarela por causa da luz, porque era a única } \\
\text { que tava tampada. E a outra, se tivesse }\end{array}$} & Configurando hipóteses
\end{tabular}
tampada, ia ficar desse jeito.

\begin{tabular}{lll}
\hline & $\begin{array}{l}\text { Professor 2: Tá bom, vamos lá. Vamos } \\
\text { pensar ó. Este daqui não tinha planta, ficou } \\
\text { do jeito que estava. Este daqui tinha planta e } \\
\text { tomou luz, ficou um pouquinho alaranjado, } \\
\text { mais vermelhinho. Esta daqui tinha planta e } \\
\text { não tomou luz, ficou meio amarelo, tá? } \\
\text { (levantando os tubos de ensaio) O que você } \\
\text { falou? (aponta para o Aluno 9). }\end{array}$ & Síntese \\
213 & $\begin{array}{l}\text { Aluno 9: Eu achei que a que não tomou luz, } \\
\text { que é isso que fez diferença, a luz. Porque as } \\
\text { outras tomaram luz. }\end{array}$ & Configurando hipóteses \\
\hline 214 & $\begin{array}{l}\text { Professor 2: Então quer dizer que o fato de } \\
\text { não tomar luz que deixa amarela. }\end{array}$ & \\
\hline & $\begin{array}{l}\text { Aluna } 6: \text { Será que a falta de luz fez com que } \\
\text { a plantinha murchasse e que ela soltasse } \\
\text { algum tipo de ácido? }\end{array}$ & Síntese \\
\hline
\end{tabular}

Fonte: elaborado pelos autores.

\section{Episódio 8}

A fim de que os alunos avançassem da configuração de hipóteses para a construção de explicações, os professores retomam os conteúdos trabalhados nos episódios anteriores. Nessa etapa, o Movimento Epistêmico predominante dos professores foi o de reelaboração, permitindo que os estudantes refletissem sobre o problema, trazendo à tona aspectos já trabalhados.

Em um primeiro momento, os professores retomam a atividade realizada com o canudo, de modo que os estudantes ordenam dados no sentido de organizar as informações que já possuem. Com a retomada, os dados prévios são comparados aos novos dados. Ao final do segmento, os alunos passam a incorporar a respiração como conhecimento conceitual 
relacionado ao problema, considerando dados e conceitos para elaborar hipóteses (Quadro $5)$.

Quadro 5 - Exemplos de turnos de fala nos quais os estudantes ordenam dados.

\begin{tabular}{|c|c|c|c|}
\hline Turno & Transcrição das falas & Práticas Epistêmicas & Movimentos Epistêmicos \\
\hline 283 & $\begin{array}{l}\text { Professor 2: Lembra lá do experimento, que } \\
\text { sopramos com o canudinho? Quando vocês } \\
\text { sopraram, vocês liberaram o quê? }\end{array}$ & & Reelaboração \\
\hline 284 & Alunos: Gás carbônico. & Ordenando dados & \\
\hline 285 & $\begin{array}{l}\text { Professor 3: Aí o gás carbônico entrou em } \\
\text { contato com a água e a reação química } \\
\text { formou ácido. Aí mudou pra que cor? }\end{array}$ & & Reelaboração \\
\hline 286 & Alunos: Laranja. & Ordenando dados & \\
\hline 287 & $\begin{array}{l}\text { Professor 3: Então nós temos o vidro } \\
\text { tampado que tá laranja, né? Tentem pensar } \\
\text { só na situação. O que tem que ser parecido } \\
\text { com o outro pra ficar igual? }\end{array}$ & & Reelaboração \\
\hline 288 & $\begin{array}{l}\text { Professor 2: Pra ele ficar laranja, ele tem que } \\
\text { ficar o quê? Pensa assim. }\end{array}$ & & \\
\hline 289 & Aluna 6: Ele tem que ter ácido. & Ordenando dados & \\
\hline 290 & $\begin{array}{l}\text { Professor 3: Aí a gente produziu o ácido } \\
\text { com o gás carbono que a gente liberou } \\
\text { soprando na água. Não foi? }\end{array}$ & & Síntese \\
\hline 291 & $\begin{array}{l}\text { Aluno 1: Eu acho que ela (a planta) jogou } \\
\text { isso na água. }\end{array}$ & Configurando hipótese & \\
\hline 292 & $\begin{array}{l}\text { Professor 3: Jogou? Como ela joga isso na } \\
\text { água? }\end{array}$ & & $\begin{array}{l}\text { Compreensão } \\
\text { Reelaboracão }\end{array}$ \\
\hline 293 & Aluno não identificado: Liberou o ácido. & Ordenando dados & \\
\hline 294 & Professor 2: E como você forma o ácido? & & Reelaboração \\
\hline 295 & Aluno 4: Soprando na água. & Ordenando dados & \\
\hline 296 & $\begin{array}{l}\text { Professor 2: Soprando na água. Como que a } \\
\text { planta então liberaria isso? }\end{array}$ & & $\begin{array}{l}\text { Confirmação } \\
\text { Reelaboração }\end{array}$ \\
\hline 297 & $\begin{array}{l}\text { Aluno 13: Aqui dentro do tubinho tinha o } \\
\text { ar? }\end{array}$ & $\begin{array}{c}\text { Considerando dados e } \\
\text { conceitos para elaborar } \\
\text { hipóteses }\end{array}$ & \\
\hline 298 & $\begin{array}{l}\text { Professor 2: Isso! O ar que você tampou, } \\
\text { que ficou aí dentro. }\end{array}$ & & Confirmação \\
\hline 299 & $\begin{array}{l}\text { Aluno 13: Tinha o ar dentro do vidro. Aí a } \\
\text { planta respirou esse ar. }\end{array}$ & $\begin{array}{l}\text { Considerando dados e } \\
\text { conceitos para elaborar } \\
\text { hipóteses }\end{array}$ & \\
\hline 300 & Professor 2: Tá. Continua. & & Confirmação \\
\hline 301 & $\begin{array}{l}\text { Aluno 13: Aí ela respirou, transformou em } \\
\text { gás carbônico e soltou. }\end{array}$ & $\begin{array}{c}\text { Considerando dados e } \\
\text { conceitos para elaborar } \\
\text { hipóteses }\end{array}$ & \\
\hline
\end{tabular}

Fonte: elaborado pelos autores. 
A sequência seguinte também tem a predominância do Movimento Epistêmico reelaboração. Os professores iniciam com uma síntese das ideias alcançadas até o momento e prosseguem, ao longo do trecho, questionando os alunos quanto à presença/ausência de luz. Isso permite que os estudantes associem a fotossíntese e a respiração ao problema, concluindo em qual tubo cada processo ocorreu. Novamente há a Prática Epistêmica ordenando dados, no sentido de organizar informações prévias (Quadro 6).

Quadro 6 - Turnos de fala nos quais as conclusões são alcançadas.

\begin{tabular}{|c|c|c|c|}
\hline Turno & Transcrição das falas & Práticas Epistêmicas & Movimentos Epistêmicos \\
\hline 309 & $\begin{array}{l}\text { Professor 3: Vamos só pegar um pouquinho } \\
\text { de cada coisa interessante. Por exemplo, } \\
\text { falaram que a luz tem influência, se está } \\
\text { aberto ou fechado tem influência. Outra } \\
\text { questão que colocaram aqui pra gente é que } \\
\text { soltou o gás carbônico e o gás carbônico em } \\
\text { contato com a água forma o ácido carbônico } \\
\text { e o ácido carbônico mudou a cor, não foi? } \\
\text { (retomando o experimento com o canudo). E } \\
\text { agora mudou a cor também. Mudou a cor } \\
\text { por quê? Ele disse (aponta para o Aluno 13) } \\
\text { que tinha oxigênio ali dentro e a planta } \\
\text { respirou, ou seja, puxou o oxigênio e soltou } \\
\text { o quê? O gás carbônico. E o gás carbônico } \\
\text { com a água vai acontecer o quê? }\end{array}$ & & $\begin{array}{c}\text { Síntese } \\
\text { Reelaboração }\end{array}$ \\
\hline 310 & Aluno 3: Virou ácido, ficou amarelo. & Ordenando dados & \\
\hline 311 & $\begin{array}{l}\text { Professor 3: Beleza. Então agora eu vou } \\
\text { perguntar, por que que aqui não? Por que } \\
\text { esse que a gente não tampou não ficou? }\end{array}$ & & $\begin{array}{l}\text { Confirmação } \\
\text { Reelaboração }\end{array}$ \\
\hline 312 & Aluno 1: Esquentou. & & \\
\hline 313 & Professor 3: Se tem luz acontece o quê? & & Reelaboração \\
\hline 314 & Alunos: A fotossíntese. & Concluindo & \\
\hline 315 & Professor 3: E se não tem luz? & & Reelaboração \\
\hline 316 & Alunos: Não acontece. & Concluindo & \\
\hline 317 & $\begin{array}{l}\text { Professor 3: Então quer dizer que aqui não } \\
\text { tem fotossíntese? (levanta o tubo que estava } \\
\text { na ausência da luz). }\end{array}$ & & Reelaboração \\
\hline 318 & Alunos: Não. & Concluindo & \\
\hline 319 & Professor: Aqui só tem o quê? & & Reelaboração \\
\hline 320 & Aluna 6: A respiração. & Concluindo & \\
\hline 321 & $\begin{array}{l}\text { Professor 3: A respiração pessoal. E aqui? } \\
\text { (levanta o tubo que recebeu luz). }\end{array}$ & & $\begin{array}{l}\text { Confirmação } \\
\text { Reelaboração }\end{array}$ \\
\hline 322 & Alunos: A fotossíntese. & Concluindo & \\
\hline 323 & $\begin{array}{l}\text { Professor 3: Só a fotossíntese aqui? Quando } \\
\text { faz fotossíntese ela (a planta) para de } \\
\text { respirar? }\end{array}$ & & Reelaboração \\
\hline 324 & Alunos: Não. & Concluindo & \\
\hline
\end{tabular}

Fonte: elaborado pelos autores. 
A seguir os professores colocam novamente aos alunos a questão sobre a coloração observada. No entanto, os estudantes permanecem calados. Então, com Movimentos Epistêmicos de reelaboração, os professores prosseguem retomando a atividade de levantamento de conhecimentos prévios. A ação permite que os alunos passem a ordenar dados de natureza teórica, no sentido de estabelecer bases conceituais para a investigação. Assim, os alunos elencam os reagentes e produtos da fotossíntese e respiração. O Quadro 7 exemplifica o momento.

Quadro 7 - Exemplos de turnos de fala nos quais os estudantes ordenam dados teóricos.

\begin{tabular}{|c|c|c|c|}
\hline Turno & Transcrição das falas & Práticas Epistêmicas & Movimentos Epistêmicos \\
\hline 331 & $\begin{array}{l}\text { Professor } 1 \text { : Vamos explicar isso mais } \\
\text { detalhadamente. Na fotossíntese, o que mais } \\
\text { que tem aqui de reagente? Além do } \mathrm{CO}_{2} \text {, o } \\
\text { que mais precisa para fazer a fotossíntese? }\end{array}$ & & Reelaboração \\
\hline 332 & Aluno 1: Luz. & & \\
\hline 333 & Aluna 6: Água. & Ordenando dados & \\
\hline 334 & Aluno 8: Clorofila. & & \\
\hline 335 & $\begin{array}{l}\text { Professor: E os produtos? Produz oxigênio e } \\
\text { o quê? }\end{array}$ & & Reelaboração \\
\hline 336 & Aluno 3: Glicose. & Ordenando dados & \\
\hline
\end{tabular}

Fonte: elaborado pelos autores.

É logo após esse momento, no turno 355, que a Aluna 6 propõe uma primeira explicação para o problema. Durante a fala, no entanto, a aluna comete um equívoco ao dizer que apenas a fotossíntese ocorreu no tubo que ficou exposto à luz. No turno seguinte os professores questionam a aluna que, em sequência, corrige sua fala. Os questionamentos dos professores sobre o gás carbônico como produto da respiração e reagente da fotossíntese nos turnos 358 e 360 , parecem fazer com que a aluna reconheça e conclua que no tubo que recebeu a luz ocorreram os dois processos. Porém, ao explicar para toda a sala, a estudante não incorpora justificativas em sua fala, apenas explicita os dados e suas conclusões para cada um dos tubos. Desse modo, no turno 369, os professores questionam a turma, direcionando-os para a construção das justificativas. O Aluno 3 inicia a listagem de produtos e reagentes envolvidos no processo e termina, no turno 365 , complementando a fala da colega. $\mathrm{O}$ estudante fornece, assim, as bases teóricas que justificam as relações expressas anteriormente. Os professores, por fim, retomam os dados empíricos ao questionarem a coloração dos frascos, de modo que o estudante reapresenta a conclusão final.

O Quadro 8 corresponde a sequência relatada, quando ao final da atividade os alunos negociam explicações, complementam ideias, utilizam conceitos para interpretar dados, articulam conhecimento observacional e conceitual e concluem. Assim, os alunos dão sentido 
aos dados a partir dos conceitos de fotossíntese e respiração, bem como as noções adquiridas sobre a formação do ácido carbônico nas atividades anteriores. Ao longo do trecho, os dados experimentais e conceitos são integrados às explicações. O Movimento Epistêmico observado para os professores é o de reelaboração, no sentido de estimular com questionamentos a formulação de conclusões e a incorporação de justificativas, direcionando a fala dos estudantes para esses elementos.

Quadro 8 - Turnos de fala nos quais os estudantes formulam a explicação para o problema.

Turno Transcrição das falas $\quad$ Práticas Epistêmicas Movimentos Epistêmicos

Aluna 6: Bom, eu acho que nessa (aluna aponta para o tubo de ensaio), como ela recebeu a luz, ela fez a fotossíntese normal e ela não liberou $\mathrm{CO}_{2}$, então não fez a mistura

355 que deu no ácido. Já nessa (aluna aponta para o outro tubo de ensaio), ela só respirou porque ela não tinha luz. Ela só respirou, o que liberou o gás carbônico, que com a junção da água virou ácido.

\section{Articulando}

conhecimento

observacional e

conceitual

Utilizando conceitos

para interpretar dados

Negociando explicações

$\begin{array}{ll} & \text { Professor 3: Mas a de cá (apontando para o } \\ 356 & \text { tubo de ensaio que estava sem papel } \\ \text { alumínio), você acha que nunca libera gás } \\ \text { carbônico? }\end{array}$

Aluna 6: Essa... liberou porque ela respirou também.
Reelaboração

$$
\begin{gathered}
\text { Articulando } \\
\text { conhecimento } \\
\text { observacional e } \\
\text { conceitual }
\end{gathered}
$$

Utilizando conceitos

para interpretar dados

Negociando explicações

\begin{tabular}{llll}
\hline 358 & $\begin{array}{l}\text { Professor 3: E o que ela fez com esse gás } \\
\text { carbônico? Pensem! O que ela fez com esse } \\
\text { gás carbônico? }\end{array}$ & Reelaboração \\
\hline 359 & Aluna 6: A fotossíntese. & Concluindo & Reelaboração \\
\hline 360 & $\begin{array}{l}\text { Professor 3: Precisa do gás carbônico pra } \\
\text { fazer a fotossíntese? }\end{array}$ & Concluindo & Reelaboração \\
\hline 361 & Aluna 6: Sim. & Concluindo & Reelaboração \\
\hline 362 & Professor 2: Você percebeu? & & \\
\hline 364 & Pluna 6: Ah, entendi! Ela respirou e também & Articulando & \\
\hline 365 & Aluna 6: Tá. Nessa aqui (aponta para os & & \\
\hline
\end{tabular}




\begin{tabular}{cc}
\hline tubos). & conhecimento \\
& observacional e \\
& conceitual \\
\hline
\end{tabular}

366 Professor 2: Pode levantar (aluna levanta a estante com os tubos de ensaio).

367 Professor 2: Só os tubinhos.

\begin{tabular}{|c|c|c|c|}
\hline 368 & $\begin{array}{l}\text { Aluna 6: As duas plantas respiram, por isso } \\
\text { essa tá mais clara. Mas essa recebeu luz, } \\
\text { então ela teve como fazer a fotossíntese, ao } \\
\text { contrário dessa. }\end{array}$ & $\begin{array}{c}\text { Articulando } \\
\text { conhecimento } \\
\text { observacional e } \\
\text { conceitual } \\
\text { Utilizando conceitos } \\
\text { para interpretar dados }\end{array}$ & \\
\hline & & Negociando explicações & \\
\hline 369 & $\begin{array}{l}\text { Professor 3: E o que acontece na } \\
\text { fotossíntese? Alguém mais pode explicar? }\end{array}$ & & Reelaboração \\
\hline 370 & Aluno 3: Ela liberou o oxigênio. & $\begin{array}{l}\text { Utilizando conceitos } \\
\text { para interpretar dados } \\
\text { Negociando explicações }\end{array}$ & \\
\hline 371 & Professor 2: E usou o quê? A luz... & & Reelaboração \\
\hline 372 & Aluno 3: O gás carbônico. & $\begin{array}{l}\text { Utilizando conceitos } \\
\text { para interpretar dados } \\
\text { Negociando explicações }\end{array}$ & \\
\hline 373 & $\begin{array}{l}\text { Professor 3: Se ela usou o gás carbônico } \\
\text { sobrou gás carbônico pra formar o ácido } \\
\text { carbônico? }\end{array}$ & & Reelaboração \\
\hline
\end{tabular}

$374 \quad \begin{aligned} & \text { Aluno 3: Não! Já quando ela respira, ela } \\ & \text { consome o oxigênio e libera o gás } \\ & \text { carbônico. }\end{aligned}$
Aluno 3: Assim, ela tá certa! (aponta para a
Aluna 6). Quando ela (a planta) faz
fotossíntese, ela vai usar o gás carbônico e
liberar o oxigênio. Já quando ela só respira,
ela vai usar o oxigênio e liberar o gás
carbônico, aí estando em contato com a
água, mudou a cor.

Utilizando conceitos

para interpretar dados

Negociando explicações

Articulando
conhecimento
observacional e
conceitual
Utilizando conceitos
para interpretar dados


Negociando explicações

Complementando ideias

\begin{tabular}{|c|c|c|c|}
\hline 376 & $\begin{array}{l}\text { Professor 3: Mas por que a diferença na cor? } \\
\text { Por que um ficou com cor e outro ficou mais } \\
\text { claro? }\end{array}$ & & Reelaboração \\
\hline 377 & $\begin{array}{l}\text { Aluno 3: É porque essa (pegou os tubos) fez } \\
\text { a fotossíntese e respirou (levanta o tubo que } \\
\text { estava aberto) e essa só respirou (levanta o } \\
\text { tudo que estava tampado). }\end{array}$ & $\begin{array}{c}\text { Articulando } \\
\text { conhecimento } \\
\text { observacional e } \\
\text { conceitual } \\
\text { Concluindo }\end{array}$ & \\
\hline 378 & $\begin{array}{l}\text { Professor 3: Se não fez a fotossíntese, não } \\
\text { usou o quê? }\end{array}$ & & Reelaboração \\
\hline 379 & Aluno 3: O gás carbônico. & $\begin{array}{l}\text { Utilizando conceitos } \\
\text { para interpretar dados }\end{array}$ & \\
\hline
\end{tabular}

Fonte: elaborado pelos autores.

A Tabela 1 apresenta os percentuais de turnos em que foram identificadas Práticas Epistêmicas, de acordo com suas instâncias sociais.

Tabela 1 - Percentuais de Práticas Epistêmicas em cada instância nos episódios 7 e 8.

\begin{tabular}{|c|c|c|c|}
\hline Instância social & Práticas Epistêmicas & Episódio 7 & Episódio 8 \\
\hline \multirow{7}{*}{ Produção } & Configurando hipóteses & $64 \%$ & $15,1 \%$ \\
\hline & Considerando dados e conceitos para elaborar hipóteses & $4 \%$ & $5,5 \%$ \\
\hline & Construindo dados & $8 \%$ & $0 \%$ \\
\hline & Ordenando dados & $8 \%$ & $31,5 \%$ \\
\hline & Articulando conhecimento observacional e conceitual & $0 \%$ & $17,8 \%$ \\
\hline & Monitorando o progresso & $8 \%$ & $0 \%$ \\
\hline & Concluindo & $0 \%$ & $13,7 \%$ \\
\hline Comunicação & Negociando explicações & $0 \%$ & $5,6 \%$ \\
\hline \multirow{3}{*}{ Avaliação } & Usando conceitos para interpretar dados & $4 \%$ & $8,6 \%$ \\
\hline & Complementando ideias & $0 \%$ & $1,4 \%$ \\
\hline & Criticando outras declarações & $4 \%$ & $1,4 \%$ \\
\hline
\end{tabular}

Fonte: elaborada pelos autores.

Para o episódio 7, a Prática Epistêmica predominante foi a configurando hipóteses. Nessa etapa, os estudantes formulavam suas hipóteses principalmente baseados na identificação da variável experimental. Já no episódio 8, a predominância foi da Prática Epistêmica ordenando dados. O desenvolvimento dessa prática pareceu importante para que os estudantes passassem do levantamento de hipóteses para a interpretação dos dados. Ao 
ordenar dados, os alunos organizaram informações previamente trabalhadas e estabeleceram bases conceituais para prosseguir com a investigação. Assim, as relações entre os dados e os conceitos puderam ser estabelecidas. É no final do episódio 8 que Práticas Epistêmicas de uma instância social de comunicação e avaliação aparecem de forma mais pronunciada, com os alunos negociando explicações, complementando ideias e utilizando conceitos para interpretar dados. Nessa etapa, a todo o momento os alunos estavam articulando conhecimento observacional e conceitual, referindo-se explicitamente aos tubos utilizados no experimento.

Nos dois episódios houve a prevalência de uma instância social de produção de conhecimento (Tabela 1). Silva (2015) também identificou uma maior frequência de práticas associadas à produção em suas análises. Segundo a autora, é esperada a predominância dessa instância em atividades investigativas, uma vez que os processos de planejamento, levantamento de hipóteses, obtenção e ordenamento de dados, mesmo para experimentos simples, demandam tempo. Além disso, a própria estrutura da atividade analisada e o modo pelo qual os professores conduziram a aula, podem ter favorecido o surgimento de determinadas Práticas Epistêmicas em detrimento de outras. A atividade central da aula envolvia a percepção dos fenômenos pela mudança de coloração ocorrida nos tubos. Os professores optaram por iniciar a aula com pequenas atividades investigativas. A estratégia possibilitou um primeiro contato dos estudantes com o indicador que seria utilizado na atividade sobre fotossíntese e respiração, de modo que os alunos construíram os dados prévios, que foram retomados posteriormente.

Ao longo do episódio 8, o Movimento Epistêmico de reelaboração dos professores teve papel importante, especialmente na retomada dos tópicos já trabalhados. É logo após as duas intervenções de retomada que uma primeira explicação para o problema é proposta. Os dados construídos em episódios anteriores sobre a ação do indicador ácido-base, bem como os conhecimentos sobre os processos de fotossíntese e respiração, foram incorporados às explicações como justificativas para a mudança de cor. Assim, os estudantes passaram a considerar outros aspectos, associando os dados obtidos, a variável experimental e os conhecimentos conceituais.

Kawasaki e Bizzo (2000) apontam que é comum os estudantes apresentarem concepções equivocadas sobre o processo de fotossíntese. A frequente oposição estabelecida entre a fotossíntese e a respiração tem conduzido à ideia de que a respiração é exclusiva dos animais, enquanto as plantas realizam apenas a fotossíntese. No caso da aula analisada, a interpretação sobre os dados obtidos no experimento permitiu aos alunos identificar a presença e complementariedade biológica dos dois processos, bem como a luz (variável experimental) como um fator para a ocorrência da fotossíntese. 


\section{Considerações finais}

Este estudo buscou identificar Práticas Epistêmicas ao longo de uma atividade prática experimental investigativa, considerando os Movimentos Epistêmicos dos professores no sentido de favorecer o desenvolvimento de determinadas práticas. Os resultados encontrados apontam que as ações dos professores, principalmente na retomada de tópicos já trabalhados, foram importantes para organização de informações, resultando na proposição de uma explicação para o problema.

Os resultados deste trabalho possibilitam uma reflexão sobre a utilização das atividades experimentais no ensino de ciências. Apontadas por muitos professores como imprescindíveis no ambiente escolar, as atividades experimentais, na maioria das vezes, se limitam à manipulação de materiais. A ausência de espaço para o exercício reflexivo ajuda a reforçar uma visão inadequada de como a ciência produz conhecimento. Em contrapartida, no decorrer da aula analisada, professores e estudantes constroem nas interações discursivas o conhecimento sobre os conceitos trabalhados. Os professores priorizaram, em seu diálogo com os alunos, uma investigação sobre os dados obtidos, incentivando-os a elaborar hipóteses, comparar dados prévios com os novos dados e incorporar conceitos que suportassem suas explicações.

Ressaltamos, por fim, que este trabalho não deve ser visto isoladamente. Ao compor parte dos referenciais que buscam analisar o desenvolvimento de Práticas Epistêmicas em aulas investigativas de ciências (e.g., LIMA-TAVARES, 2009; SILVA, 2011; 2015; NASCIMENTO et al., 2014), este e os demais estudos de caso podem contribuir para elucidar quais são as práticas envolvidas, como as ações do professor favorecem seu aparecimento, sua relação com a aprendizagem de conceitos científicos e as próprias estruturas das atividades que são propostas.

\section{Referências}

AXT, R. O papel da experimentação no Ensino de Ciências. In: MOREIRA, M. A.; AXT, R. (Org.) Tópicos em ensino de Ciências. Porto Alegre: Sagra, 1991. p. 79-90.

BORGES, A. T. Novos rumos para o laboratório escolar de ciências. Cad. Bras. Ens. Fís., v. 19, n. 3, p. 291-313, 2002.

BRASIL. Ministério da Educação. Secretaria de Educação Fundamental. Parâmetros Curriculares Nacionais: Ciências ( $3^{\circ}$ e $4^{\circ}$ ciclos do ensino fundamental). Brasília: MEC, 1998.

CARVALHO, A. M. P. Las prácticas experimentales en el proceso de enculturación científica. In: GATICA, M. Q.; ADÚRIZ-BRAVO, A. (Org.) Enseñar ciencias en el Nuevo 
milenio: retos y propuestas. Santiago: Ediciones Universidad Católica de Chile, 2006. p. 7390 .

CARVALHO, A. M. P. O Ensino de Ciências e a proposição de sequências de ensino investigativas. In: CARVALHO, A. M. P. (Org.) Ensino de Ciências por investigação: Condições para implementação em sala de aula. São Paulo: Cengage Learning, 2013. p. 1-20.

FILHO, B. B. Atividades Práticas na $8^{a}$ Série do Ensino Fundamental: luz numa abordagem regionalizada. Dissertação de mestrado em Educação - Faculdade de Educação, Universidade Estadual de Campinas, Campinas, 2001.

GALIAZZI, M. C.; ROCHA, J. M. B.; SCHMITZ, L. C.; SOUZA, M. L.; GIESTA, S.; GONÇALVES, F. P. Objetivos das atividades experimentais no Ensino Médio: a pesquisa coletiva como modo de formação de professores de Ciências. Ciência \& Educação, v. 7, n. 2, p. 249-263, 2001.

GIL PERÉZ, D.; CASTRO, P. V. La orientación de las prácticas de laboratorio como investigación: un ejemplo ilustrativo. Enseñanza de las Ciencias, v. 14, n. 2, p. 155-163, 1996.

GIORDAN, M. Computadores e linguagens nas aulas de ciências: uma perspectiva sociocultural para compreender a construção dos significados. Ijuí: Editora Unijuí, 2008.

HODSON, D. Hacia un enfoque más crítico del trabajo de laboratorio. Enseñanza de las Ciencias, v. 12, n. 3, p. 299-313, 1994.

JIMÉNEZ-ALEIXANDRE, M. P. A argumentação sobre questões sociocientíficas: processos de construção e justificação do conhecimento na aula. Educação em revista, v. 43, p.13-33, 2006.

JIMÉNEZ-ALEIXANDRE, M. P.; DÍAZ, J. B.; DUSCHL, R. A. Scientific Culture and School Culture: Epistemic and Procedural Components. In: ANNUAL MEETING OF THE NATIONAL ASSOCIATION OF RESEARCH IN SCIENCE TEACHING, 1998, San Diego. Proceedings... San Diego: NARST, 1998.

JIMÉNEZ-ALEIXANDRE, M. P.; MORTIMER, R. F.; SILVA, A. C. T.; DÍAZ, J. B. Epistemic Practices: an Analytical Framework for Science Classrooms. In: ANNUAL MEETING OF THE AMERICAN EDUCATIONAL RESEARCH ASSOCIATION, 2008, New York. Proceedings... New York: AERA, 2008.

KAWASAKI, C. S.; BIZZO, N. M. V. Fotossíntese: um tema para o ensino de ciências? Química Nova na Escola, n. 12, p. 24-29, 2000.

KELLY, G. J. Inquiry, Activity, and Epistemic Practices. In: INQUIRY CONFERENCE ON DEVELOPING A CONSENSUS RESEARCH AGENDA, 2005, New Brunswick.

Proceedings... New Brinswick: Rutgers University, 2005.

KELLY, G. J.; DUSCHL, R. A. Toward a research agenda for epistemological studies in science education. In: ANNUAL MEETING OF THE NATIONAL ASSOCIATION OF RESEARCH IN SCIENCE TEACHING, 2002, New Orleans. Proceedings... Reston: NARST, 2002. 
KELLY, G. J; TAKAO, A. Epistemic levels in argument: an analysis of university oceanography students' use of evidence in writing. Science Education, v. 86, n. 3, p. 314-342, 2002.

LEMKE, J. L. Talking science: Language, Learning, and Values. Norwood: Ablex Publishing, 1990.

LIDAR, M; LUNDQVIST, E.; ÖSTMAN, L. Teaching and learning in the science classroom: the interplay between teachers' epistemological moves and students' practical epistemology. Science Education, v. 90, n. 1, p. 148-163, 2005.

LIMA-TAVARES, M. Argumentação em sala de aula de biologia sobre a teoria sintética da evolução. Tese de doutorado em Educação em Ciências - Faculdade de Educação,

Universidade Federal de Minas Gerais, Belo Horizonte, 2009.

MORTIMER, E. F.; MASSICAME, T.; TIBERGHIEN, A.; BUTY, C. Uma metodologia para caracterizar os gêneros de discurso como tipos de estratégias enunciativas nas aulas de ciências. In: NARDI, R. (Org.) A pesquisa em ensino de ciências no Brasil: alguns recortes. São Paulo: Escrituras, 2007. p. 53-94.

MORTIMER, E. F.; SCOTT, P. H. Meaning making in secondary science classrooms. Buckingham: Open University Press, 2003.

NASCIMENTO, E. D. O.; SILVA, A. C. T.; FRANÇA, E. C. M. Práticas epistêmicas e movimentos epistêmicos de cada categoria, relacionando-as em uma atividade investigativa de ciências. In: COLÓQUIO INTERNACIONAL "EDUCAÇÃO E CONTEMPORANEIDADE”, 6., 2012, São Cristóvão. Anais... São Cristóvão: EDUCON, 2012.

RABONI, P. C. A. Atividades práticas de ciências naturais na formação de professores para as séries iniciais. Tese de doutorado em Educação - Faculdade de Educação, Universidade Estadual de Campinas, Campinas, 2002.

RAMOS, L. B. C.; ROSA, P. R. S. O ensino de ciências: fatores intrínsecos e extrínsecos que limitam a realização de atividades experimentais pelo professor dos anos iniciais do ensino fundamental. Investigações em Ensino de Ciências, v. 13, n. 3, p. 299-331, 2008.

SANDOVAL, W. A.; MORRISON, K. High school students' ideas about theories and theories change after a biological inquiry unit. Journal of research in science teaching, v. 40, n. 4, p. 369-393, 2003.

SANDOVAL, W. A.; REISER, B. J. Explanation-driven inquiry: integrating conceptual and epistemic scaffolds for scientific inquiry. Science Education, v. 88, n. 3, p. 345-372, 2004.

SILVA, A. C. T. Estratégias enunciativas em salas de aula de química: contrastando professores de estilos diferentes. Tese de doutorado em Educação - Universidade Federal de Minas Gerais, Belo Horizonte, 2008.

SILVA, A. C. T. Práticas e movimentos epistêmicos em atividades investigativas de química. In: ENCONTRO NACIONAL DE PESQUISA EM EDUCAÇÃO EM CIÊNNCIAS, 8., 2011, Campinas. Anais... Campinas: ABRAPEC, 2011.

SILVA, A. C. T. Interações discursivas e práticas epistêmicas em salas de aula de ciências. Ensaio Pesquisa em Educação em Ciências, v. 17, p. 69-96, 2015. Número especial. 
SILVA, L. H. A.; ZANON, L. B. A experimentação no ensino de ciências. In: SCHNETZLER, R. P.; ARAGÃO, R. M. R. (Org.) Ensino de Ciências: fundamentos e abordagens. Piracicaba: CAPES/UNIMEP, 2000. p. 120-153.

TAKAO, A. Y.; KELLY, G. J. Assessment of evidence in university students' scientific writing. Science \& Education, v. 12, n. 4, p. 341-363, 2003.

ZÔMPERO, A. F., LABURÚ, C. E. Atividades investigativas no ensino de ciências: Aspectos históricos e diferentes abordagens. Ensaio Pesquisa em Educação em Ciências, v. 13, n. 3, p. 67-80, 2011.

\section{Agradecimentos}

Os autores agradecem ao Grupo de Pesquisa Linguagem e Ensino de Ciências (LINCE) da Faculdade de Filosofia, Ciências e Letras de Ribeirão Preto (FFCLRP), Universidade de São Paulo (USP). A escola participante e ao PIBID, que possibilitaram o desenvolvimento do estudo. Ao Prof. Dr. Marcelo Giordan, pelas discussões realizadas durante a disciplina "Perspectivas Socioculturais para Investigar a Dinâmica das Interações da Sala de Aula de Ciências" (Faculdade de Educação, Universidade de São Paulo) e as sugestões dadas sobre o manuscrito. Ao Programa de Pós-Graduação Interunidades em Ensino de Ciências, Universidade de São Paulo (USP). A CAPES pela bolsa de mestrado concedida à primeira autora.

\section{SOBRE OS AUTORES}

ANA ELISA MONTEBELLI MOTTA. Bacharela (2014) e Licenciada (2015) em Ciências Biológicas pela Faculdade de Filosofia, Ciências e Letras de Ribeirão Preto (FFCLRP), Universidade de São Paulo (USP). Especialista em Jornalismo Científico (2016) pelo Laboratório de Estudos Avançados em Jornalismo (LABJOR), Universidade Estadual de Campinas (UNICAMP). Atualmente é mestranda do Programa Interunidades em Ensino de Ciências (modalidade Biologia), Universidade de São Paulo (USP), e membro do grupo de pesquisa Linguagem e Ensino de Ciências (LINCE).

MICHELE DAYANE FACIOLI MEDEIROS. Licenciada em Ciências Biológicas (2006) pelo Centro Universitário Barão de Mauá. Especialista em Educação Ambiental e Desenvolvimento Sustentável (2010) e em Educação Escolar - Desafios do Cotidiano (2011) pela Faculdade de Educação São Luís (FESL). Especialista em Gestão Ambiental (2010) pela Universidade Federal de São Carlos (UFSCAR). Mestre em Ensino de Ciências (modalidade Biologia) (2016) pelo Programa Interunidades em Ensino de Ciências, Universidade de São Paulo (USP). Membro do grupo de pesquisa Linguagem e Ensino de Ciências (LINCE). Atua como professora da rede pública estadual e municipal desde 2010 e é supervisora do Programa Institucional de Bolsa de Iniciação à Docência (PIBID) desde 2014. Atualmente é doutoranda do Programa Interunidades em Ensino de Ciências (modalidade Biologia), Universidade de São Paulo (USP).

MARCELO TADEU MOTOKANE. Bacharel e Licenciado em Biologia (1992) pela Universidade de São Paulo (USP). Mestre (2000) e doutor (2005) em Educação pela Universidade de São Paulo (USP). Atualmente é professor do Departamento de Biologia da Faculdade de Filosofia, Ciências e Letras (FFCLRP), Universidade de São Paulo (USP). Tem experiência na área de Educação, com ênfase em Ensino de Ciências, atuando principalmente nos seguintes temas: argumentação no ensino de ciências e biologia, linguagem e ensino de ciências, educação ambiental, formação de professores de ciências e biologia. É orientador do Programa de Pós-Graduação Interunidades em Ensino de Ciências (modalidade Biologia) e do 
Programa de Pós-Graduação em Biologia Comparada, ambos da Universidade de São Paulo (USP). Coordena o grupo de pesquisa Linguagem e Ensino de Ciências (LINCE) e o Laboratório de Ensino de Biologia (LEB) do Departamento de Biologia da Faculdade de Filosofia, Ciências e Letras de Ribeirão Preto (FFCLRP).

ANEXO I - Síntese da Sequência Didática Investigativa "Características básicas dos seres vivos"

\begin{tabular}{|c|c|c|}
\hline Aula & Tema central & Tópicos \\
\hline 1 & \multirow{4}{*}{ Célula } & Diversidade da vida microscópica \\
\hline 2 & & Níveis organizacionais \\
\hline 3 & & Variedade de formas celulares \\
\hline 4 & & O conceito de célula \\
\hline 5 & \multirow{2}{*}{ Energia } & Fotossíntese e respiração \\
\hline 6 & & Fermentação \\
\hline 7 & Reprodução & Reprodução sexuada e assexuada \\
\hline 8 & Sistematização & Retomada dos conceitos trabalhados \\
\hline
\end{tabular}

Recebido: 27 de setembro de 2017.

Revisado: 25 de abril de 2018.

Aceito: 12 de julho de 2018. 